\title{
ATIVIDADE ENZIMÁTICA E ANTIMICROBIANA DE FUNGOS ENDOFÍTICOS ISOLADOS DE SOJA
}

\section{Juliana Bernardi Wenzel}

Mestre em Biologia das Interações Orgânicas/Universidade Paranaense - UNIPAR - Unidade Toledo/PR

julianab@unipar.br

\author{
Adriana Aparecida de Almeida Moresco \\ Bióloga/Universidade Paranaense - UNIPAR - Unidade Toledo/PR \\ adriana.moresco@hotmail.com
}

\section{Edilene Vilas Boas}

Acadêmica de Ciências Biológicas/Universidade Paranaense - UNIPAR - Unidade Toledo/PR edilene_vb@hotmail.com

\section{Flávia Angélica Gonçalvez Burin}

Bióloga//Universidade Paranaense - UNIPAR - Unidade Toledo/PR

douglas-flavia@hotmail.com

\section{Rodrigo Onofre de Souza}

Acadêmico de Ciências Biológicas/Universidade Paranaense - UNIPAR - Unidade Toledo/PR

rodrigoonofresouza@bol.com.br

Recebido: 01 de junho de 2013. Revisado: 16 de julho de 2013. Aceito: 17 de julho de 2013. Publicado online: 17 de julho de 2013.

\section{RESUMO}

Devido às potencialidades dos fungos endofíticos como produtores de compostos com atividade antimicrobiana e pela capacidade de produção de enzimas extracelulares, este trabalho teve como objetivo avaliar a atividade antimicrobiana e enzimática de fungos endofíticos isolados de soja. Para avaliação da atividade antimicrobiana, 23 fungos endofíticos foram testados a partir do meio fermentado, acetato de etila e metanol. Foi utilizado o teste de difusão em discos contra as bactérias patogênicas humanas Escherichia coli, Staphylococcus aureus, Salmonella enterica, Shigella flexneri e Micrococcus luteus. Em placas de Petri com meio LB contendo as bactérias foram inseridos quatro discos de papel estéreis inoculados com $10 \mu \mathrm{L}$ de cada extrato metabólito. As placas foram incubadas a $37^{\circ} \mathrm{C}$ por $24 \mathrm{~h}$. Avaliou-se a atividade antimicrobiana pela formação de halos de inibição. $\mathrm{O}$ potencial enzimático foi avaliado para a produção das enzimas extracelulares como proteases, lipases e amilases pela formação de halo de degradação de seus respectivos substratos em meio mínimo. Quanto à atividade antimicrobiana, nove isolados apresentaram potencial antibacteriano para pelo menos uma das cinco bactérias patogênicas testadas. Em relação a atividade enzimática 20 isolados apresentaram atividade amilolítica e três proteolítica, com atividade fortemente positiva para ambas e não apresentandoatividade lipolítica para nenhum dos isolados.

Palavras-chave: Glycine max, enzimas, halo, bactérias patogênicas. 


\begin{abstract}
Due to the potential of endophytic fungi as producers of compounds with antimicrobial activity and the ability to produce extracellular enzymes, the aim of the present study was to evaluate the antimicrobial and enzymatic activity of endophytic fungi isolated from soybean. For antimicrobial activity, 23 endophytic fungi were tested from the fermentation broth, ethyl acetate and methanol. Test was used disc diffusion against human pathogenic bacteria Escherichia coli, Staphylococcus aureus, Salmonella enterica, Shigella flexneri and Micrococcus luteus. In Petri dishes with LB medium containing bacteria were inserted four sterile paper disks inoculated with $10 \mu \mathrm{L}$ of each extract metabolite. The dishes were incubated at $37^{\circ} \mathrm{C}$ for $24 \mathrm{~h}$. We evaluated the antimicrobial activity by the evidence of a zone of inhibition. The enzymatic potential was evaluated for production of extracellular enzymes proteases, lipases and amylases by the clear halos formation of these degradation on minimal medium. Nine isolates showed antibacterial potential for at least one of five pathogenic bacteria tested. As the enzymatic activity 20 isolates show the amylolytic activity, three proteolytic activity, with a strong positive activity for both and no lipase activity show for any of the isolates.
\end{abstract}

Keywords: Glycine max, enzymes, halo, pathogenic bacteria.

\title{
1. INTRODUÇÃO
}

A soja (Glycine max (L.) Merr.) é uma das culturas mais difundidas no Brasil, possuindo grande importância nutricional e industrial, sendo o país o segundo maior produtor mundial (EMBRAPA/SOJA, 2012). Assim como as demais plantas pesquisadas até hoje, a soja possui diversidade de fungos endofíticos e por ser uma cultura abundante pode ser utilizada como fonte de fungos com potencial biotecnológico (BERNARDI-WENZEL et al., 2012).

Micro-organismos endofíticos podem ser encontrados habitando inter e intracelularmente os tecidos vegetais (BERNARDI-WENZEL et al., 2010), sendo encontrados em todas as espécies de plantas já investigadas, porém com incidência variando de acordo com o hospedeiro, distribuição geográfica, idade da planta, condições ecológicas e sazonais (BLODGETT et al., 2007). Frequentemente uma ou duas espécies são predominantes como endofíticas em um dado hospedeiro, enquanto outras são menos frequentes (CARROLL \& CARROLL, 1978; ARNOLD et al., 2003). Essa associação íntima entre espécies de endófitos e as espécies vegetais, indica a possibilidade de coevolução destas espécies (SAIKKONEN et al., 2004), que devido a associação simbiôntica vivem sem causar danos ao hospedeiro (PAMPHILE \& AZEVEDO, 2002), podem gerar benefícios à planta que os alberga e ainda produzir substâncias de interesse para indústrias como antimicrobianos, antioxidantes (STROBEL \& DAISY, 2003) e enzimas extracelulares (CUZZI et al., 2011).

Assim, os endofíticos constituem uma valiosa fonte para obtenção de novas biomoléculas com diferentes e variadas propriedades (FIRÁKOVÁ et al., 2007), sendo que muitas espécies já isoladas são reconhecidas como fontes de metabólitos secundários bioativos (STROBEL, 2003). Para avaliação das possíveis aplicações biotecnológicas destes metabólitos, o isolamento e identificação de espécies de endofíticos são os primeiros passos para que se possa posteriormente contribuir com a descoberta de novas moléculas com atividade antimicrobiana, principalmente em países de grande biodiversidade como o Brasil, em que as perspectivas para o estudo são bastante promissoras (PEIXOTO-NETO et al., 2002).

A produção de metabólitos secundários pelos fungos endofíticos pode ser influenciada pelas condições ambientais, bem como pelo estado fisiológico do hospedeiro, sendo alguns destes fatores capaz de alterar as condições internas da planta, levando a mudança do ambiente ao redor do endófito, que para se adaptar a essa nova condição pode produzir compostos que irão atuar neste processo (AZEVEDO et al., 2002).

Persp. online: biol. \& saúde, Campos dos Goytacazes, 9 (3), 01-15, 2013

seer.perspectivasonline.com.br 
A obtenção desses metabólitos bioativos é realizada por diferentes metodologias de extração que visam separar compostos de acordo com a polaridade, utilizando o próprio meio fermentado (SOUZA et al., 2004), solventes como metanol (SILVA et al., 2002), acetato de etila, clorofórmio, etanol e acetona (CUNHA et al., 2009). Após o procedimento de extração esses metabólitos são concentrados, sua atividade testada, e em caso de positividade no controle de outro micro-organismo patogênico, o composto é identificado e patenteado, podendo ser utilizado na forma de fármacos (LI et al., 2005). Diversos compostos produzidos por fungos endofíticos já foram descritos na literatura, como os esteroides (MARINHO et al., 2009), ácidos fenólicos, alcaloides, fenilpropanoides, (ZHANG et al., 2006), citocalasinas, isocumarinas, terpenos, benzopiranos, tetralonas (CHAPLA et al., 2012).

Entre os compostos produzidos pelo metabolistmo secundário de fungos endofíticos isolados de diferentes plantas, muitos podem apresentar atividade antimicrobiana contra bactérias e fungos patogênicos como aqueles isolados de Coffea arabica L. e C. robusta (L.) Linden na bioatividade contra Pseudomonas aeruginosa (Schroeter 1872) Migula 1900, Salmonella Lignieres 1900, Staphylococcus aureus Rosenbach 1884 (SETTE et al., 2006), de Quercus variabilis Blume, contra Escherichia coli (Migula 1895) Castellani and Chalmers 1919, Bacillus subtilis (Ehrenberg 1835) Cohn 1872, P. fluorescens Migula 1895, Trichophyton rubrum (Castell.) Sabour., Candida albicans (C.P. Robin) Berkhout, Aspergillus niger Tiegh., Epidermophyton floccosum (Harz) Langeron \& Miloch. e Microsporum canis E. Bodin ex Guég. (WANG et al., 2007) e de Palicourea longiflora DC. e Strychnos cogens Benth. contra E. coli, B. subtilis, S. aureus, Trichoderma Pers. e A. flavus Link (SOUZA et al., 2004).

$\mathrm{Na}$ íntima relação entre endófito e planta hospedeira também pode ocorrer produção de enzimas extracelulares que podem ser purificadas para uso em diferentes indústrias (ESPOSITO \& AZEVEDO, 2004), dentre elas as proteases, lipases e amilases. Entre elas, as proteases são enzimas que catalizam clivagem das ligações peptídicas das protéinas, podendo ser extraídas de diversos organismos, incluindo bactérias, fungos, leveduras, tecidos de mamíferos e de plantas, porém tem o custo reduzido quando obtidas à partir de microorganismos como os do gênero Bacillus (SELLAMI-KAMOUN et al., 2008). De acordo com Beynon \& Bond (1989), estas enzimas apresentam grande importância para indústrias no processamento de alimentos, bebidas, formulação de medicamentos e detergentes, amaciamento de carnes, formulação de medicamentos, indústria têxtil e de couro (FOUKIS et al., 2012).

As lipases são enzimas utilizadas para a hidrólise de óleos e gorduras de cadeia longa liberando ácidos graxos de baixo peso molecular (BIER, 1955). A produção é realizada por micro-organismos em meio líquido ou em meio sólido, sendo que a última tem sido relatada principalmente para fungos filamentosos e pouco para bactérias e leveduras, com amplas aplicações industriais, tais como: na geração de cosméticos e perfumarias; nas indústrias de alimentos, químicas e farmacêutica e, na indústria de combustíveis (MESSIAS et al., 2011).

As amilases estão entre as enzimas mais importantes para as indústrias, sendo responsáveis pela hidrólise do amido e tendo aplicação em indústrias têxteis, de bebidas, panificação, de detergentes, ração animal, química e farmacêutica (WIT, 1989). Assim como as demais enzimas citadas anteriormente, as amilases de origem microbiana, geralmente encontram grandes demandas industriais (GUPTA et al., 2003).

Diante do exposto, o objetivo deste trabalho foi avaliar a atividade antimicrobiana e a produção de enzimas extracelulares por fungos endofíticos isolados de plantas de soja.

Persp. online: biol. \& saúde, Campos dos Goytacazes, 9 (3), 01-15, 2013

seer.perspectivasonline.com.br 


\section{METODOLOGIA}

\subsection{Obtenção dos fungos endofíticos}

Os fungos utilizados neste trabalho foram isolados a partir de folhas de soja por BernardiWenzel et al. (2012), discriminados como C1 à C32. Alguns isolados foram identificados como espécies pertencentes aos gêneros Aspergillus P. Micheli (C2, C14, C15, C16 e C32), Phomopsis Sacc. \& Roum. (C11 e C21), Bipolaris Shoemaker (C8 e C22), Nectria (Fr.) Fr. (C5), Nigrospora Zimm. (C7), Fusarium Link (C31), Penicillium Link (C24), Phoma Fr. (C3 e C26), Alternaria Nees (C18), Botryotrichum Sacc. \& Marchal (C1), Leptosphaerulina McAlpine (C6 e C20), Acrospeira Berk. \& Broome (C10), Scopulariopsis Bainier (C13) Trichothecium Link (C28), Papulaspora Preuss (C29) e outros isolados não-identificados.

\subsection{Obtenção de metabólitos secundários}

Para obtenção de metabólitos secundários foi utilizada a metodologia de Li et al. (2005), modificada. Os fungos foram semeados em meio líquido BD (batata dextrose) (Smith \& Onions, 1983), em erlenmeyers de $500 \mathrm{~mL}$ e incubados a $25{ }^{\circ} \mathrm{C}$ por nove dias em agitador orbital com $160 \mathrm{rpm}$. O meio fermentado foi coletado e centrifugado a $3.600 \mathrm{rpm}$ por 10 minutos. O sobrenadante foi dividido em dois e metade utilizado para o teste diretamente do meio fermentado e a outra metado colocado em um funil de separação ao qual foi adicionado o mesmo volume de acetato de etila P.A. O funil foi agitado e as fases foram separadas. A extração foi repetida mais duas vezes. $O$ acetato de etila resultante da extração foi concentrado em evaporador rotativo a $50{ }^{\circ} \mathrm{C}$. O material resultante da evaporação foi diluído com $1 \mathrm{~mL}$ de metanol absoluto e estocado a $4{ }^{\circ} \mathrm{C}$. Foi também utilizada extração de metabólitos diretamente do micélio coletado na superfície no meio. O micélio foi filtrado e foi mantido por 24 horas em metanol. Após este período foi centrifugado e o sobrenadante foi coletado e concentrado em evaporador rotativo a $50{ }^{\circ} \mathrm{C}$.

\subsection{Avaliação da atividade antimicrobiana}

A atividade antimicrobiana foi testada utilizando ensaios biológicos qualitativos, em triplicata. Os micro-organismos utilizados no teste foram as bactérias patogênicas humanas $E$. coli (ATCC 25922), Salmonella sp. (ATCC 19430), Shigella flexneri Castellani and Chalmers, 1919 (ATCC 12022), Micrococcus luteus (Schroeter 1872) Cohn 1872 (ATCC 9341) e $S$. aureus (ATCC 25923).

Para os testes foi utilizada a técnica de difusão em disco dos extratos obtidos dos isolados endofíticos em acetato de etila, metanol e o próprio meio fermentado. As bactérias foram crescidas a $37{ }^{\circ} \mathrm{C}$ por 24 horas em meio líquido LB (Luria Bertani) (Sambrook and Russel, 2001), ajustadas a uma concentração de $10^{6}$ células. $\mathrm{mL}^{-1}$, utilizando a escala de MacFarland. As bactérias foram semeadas $(100 \mu \mathrm{L})$ em placas de Petri contendo meio LB realizando-se o espalhamento com alça de Drigalsky. Posteriormente foram inseridos quatro discos papel Watman $\mathrm{n}^{\mathrm{o}} 4$ estéreis ( $66 \mathrm{~mm}$ ), equidistantes, embebidos com $10 \mu \mathrm{L}$ do extrato metabólito. As placas foram incubadas a $37{ }^{\circ} \mathrm{C}$ por 24 horas. A atividade antimicrobiana foi avaliada pela formação e medida do halo de inibição, adaptado de Souza et al. (2004).

As médias dos halos obtidos foram avaliadas estatisticamente por análise de variância (ANOVA) e comparadas pelo teste de Tukey $(\mathrm{p}<0,05)$ com auxílio do programa estatístico SISVAR (FERREIRA, 2000).

\subsection{Avaliação da atividade enzimática}

Para a avaliação da produção das enzimas hidrolíticas extracelulares amilase e lipase foi utilizada a metodologia de Hankin \& Anagnostakis (1975) e para protease a metodologia descrita por Cuzzi et al. (2011). Foram testados 24 isolados, cultivados por sete dias em meio 
BDA. O experimento foi montado em DIC com 24 tratamentos (diferentes isolados) e três repetições, sendo a unidade experimental constituída por uma placa de Petri contendo um disco de micélio do fungo endofítico em Meio Mínimo (MM) (Pontecorvo et al., 1953).

\subsubsection{Atividade proteolítica}

Para a atividade proteolítica as espécies fúngicas foram semeadas no centro de cada placa contendo meio minimo (MM), suplementado com 2\% de albumina (proteína bovina), pH 6,5 e mantidas em estufa a $28{ }^{\circ} \mathrm{C}$, por sete dias. Para a determinação do halo de degradação as placas foram impregnadas com azul de comassie.

\subsubsection{Atividade amilolítica}

Para a atividade amilolítica os fungos foram semeados no centro da placa contendo MM, suplementado com amido solúvel $2 \%$ e pH 6,0. As placas foram incubadas a $28{ }^{\circ} \mathrm{C}$, por sete dias. Após esse período, as placas foram reveladas com lugol. A reação de degradação do amido pela amilase pode ser verificada, após a adição do lugol, pela coloração azul-preto do amido e a zona de degradação em torno das colônias permanece marrom manchado ou incolor.

\subsubsection{Atividade lipolítica}

Para a atividade lipolítica os fungos foram semeados no centro da placa contendo MM, suplementado com $2 \%$ de Polissorbato 80 , em pH 6,5. As placas foram mantida em estufa de crescimento a $28^{\circ} \mathrm{C}$, por sete dias. Posteriormente, essas placas foram transferidas para um refrigerador e mantidas por mais sete dias a $4^{\circ} \mathrm{C}$, quando foram realizadas as avaliações. A atividade lipolítica foi evidenciada pela presença de cristais de sais de cálcio do ácido láurico, liberados ao redor das colônias formando um halo.

\subsubsection{Determinação da atividade enzimática}

A determinação da atividade enzimática $(\mathrm{Pz})$ foi realizada conforme descrito por Cuzzi et al. (2011), onde a atividade $(\mathrm{Pz})$ de cada espécie decorreu da razão entre o diâmetro da colônia (dc) e o diâmetro da colônia mais a área de precipitação (dcp), ou seja, o diâmetro de crescimento fúngico mais a área do halo de degradação. Todas as atividades foram avaliadas em triplicata, sendo obtido a $\mathrm{Pz}$ pela média das triplicatas e os resultados foram classificados como negativos $(\mathrm{Pz}=1$, classe 1$)$, positivos $(0,64=\mathrm{Pz}<1$, classe 2$)$ e fortemente positivos $(\mathrm{Pz}<0,64$,classe 3), em que $\mathrm{Pz}=\mathrm{dc} / \mathrm{dcp}$.

\section{RESULTADOS E DISCUSSÃO}

Quanto aos metabólitos secundários de fungos endofíticos obtidos de folhas de soja e extraídos com acetato de etila, os isolados C12, C21 e C23 apresentaram atividade antimicrobiana destacada contra $S$. aureus, C1 e C4 contra $S$. flexneri e C17, C20, C21 e C23 contra $M$. luteus, diferindo-se significativamente do controle. Para E.coli e S. enterica não houve atividade significativa, sendo semelhantes ao controle (Tabela 1). Já os metabólitos secundários de fungos endofíticos isolados de soja e extraídos com álcool metílico não apresentaram diferenças significativas em relação ao controle (Tabela 2). Em relação aos metabólitos secundários obtidos diretamente do meio fermentado, aqueles produzidos pelo isolado C17 e pelos isolados C14 e C20 apresentaram atividade antimicrobiana contra E.coli e S. enterica, respectivamente, bem como os metabábólitos produzidos por C2 contra S. flexneri e C12 e C20 contra M. Luteus. Todos estes diferiram significativamente do controle (Tabela 3). O meio fermentado obtido dos demais isolados não apresentou diferença em relação ao controle.

Persp. online: biol. \& saúde, Campos dos Goytacazes, 9 (3), 01-15, 2013

seer.perspectivasonline.com.br 
TABELA 1: Médias dos halos de inibição $(\mathrm{cm})$ produzidos por metabólitos de fungos endofíticos isolados de soja e extraídos em acetato de etila frente a bactérias patogênicas humanas

\begin{tabular}{|c|c|c|c|c|c|}
\hline Isolado & $\begin{array}{c}\text { Escherichia } \\
\text { coli }\end{array}$ & $\begin{array}{c}\text { Staphylococcus } \\
\text { aureus }\end{array}$ & $\begin{array}{c}\text { Salmonella } \\
\text { enterica }\end{array}$ & $\begin{array}{l}\text { Shigela } \\
\text { flexneri }\end{array}$ & $\begin{array}{c}\text { Micrococcus } \\
\text { luteus }\end{array}$ \\
\hline C1 (Botryotrichum sp.) & $8,12^{\mathrm{a} *}$ & $8,50^{\mathrm{abc}}$ & $7,50^{\mathrm{a}}$ & $12,87^{\mathrm{C}}$ & $7,37^{\mathrm{ab}}$ \\
\hline C2 (Aspergillus sp.) & $6,87^{\mathrm{a}}$ & $7,77^{\mathrm{abc}}$ & $7,12^{\mathrm{a}}$ & $7,37^{\mathrm{a}}$ & $10,12^{\mathrm{abc}}$ \\
\hline C4 (não identificado) & $6,12^{\mathrm{a}}$ & $7,00^{\mathrm{ab}}$ & $7,25^{\mathrm{a}}$ & $10,75^{b c}$ & $7,12^{\mathrm{ab}}$ \\
\hline C7 (Nigrospora sp.) & $6,62^{\mathrm{a}}$ & $7,50^{\mathrm{abc}}$ & $7,00^{\mathrm{a}}$ & $9,12^{\mathrm{ab}}$ & $7,00^{\mathrm{ab}}$ \\
\hline C8 (Bipolaris sp.) & $7,50^{\mathrm{a}}$ & $7,87^{\mathrm{abc}}$ & $8,00^{\mathrm{a}}$ & $8,25^{\mathrm{a}}$ & $9,75^{\mathrm{abc}}$ \\
\hline $\mathrm{C} 10$ (Acrospeira sp.) & $8,12^{\mathrm{a}}$ & $8,12^{\mathrm{abc}}$ & $7,75^{\text {a }}$ & $8,87^{\mathrm{ab}}$ & $7,00^{\mathrm{ab}}$ \\
\hline C11(Phomopsis sp.) & $7,75^{\mathrm{a}}$ & $7,37^{\mathrm{ab}}$ & $7,00^{\mathrm{a}}$ & $10,12^{\mathrm{ab}}$ & $7,00^{\mathrm{ab}}$ \\
\hline C12 (não identificado) & $7,50^{\mathrm{a}}$ & $10,75^{\mathrm{c}}$ & $6,50^{\mathrm{a}}$ & $8,25^{\mathrm{a}}$ & $10,37^{\mathrm{abc}}$ \\
\hline C13 (Scopulariopsis sp.) & $7,25^{\mathrm{a}}$ & $7,75^{\mathrm{abc}}$ & $7,37^{\mathrm{a}}$ & $9,37^{\mathrm{ab}}$ & $7,25^{\mathrm{ab}}$ \\
\hline C14 (Aspergillus sp.) & $7,00^{\mathrm{a}}$ & $7,87^{\mathrm{abc}}$ & $7,25^{\mathrm{a}}$ & $9,75^{\mathrm{ab}}$ & $8,87^{\mathrm{abc}}$ \\
\hline C16 (Aspergillus sp.) & $7,25^{\mathrm{a}}$ & $8,00^{\mathrm{abc}}$ & $7,37^{\mathrm{a}}$ & $8,50^{\mathrm{ab}}$ & $7,25^{\mathrm{ab}}$ \\
\hline $\mathrm{C} 17$ (Mucor sp.) & $7,50^{\mathrm{a}}$ & $8,25^{\mathrm{abc}}$ & $7,50^{\mathrm{a}}$ & $7,00^{\mathrm{a}}$ & $11,62^{\mathrm{d}}$ \\
\hline C18 (Alternaria sp.) & $7,50^{\mathrm{a}}$ & $8,00^{\mathrm{abc}}$ & $7,62^{\mathrm{a}}$ & $8,12^{\mathrm{a}}$ & $8,00^{\mathrm{abc}}$ \\
\hline C19 (não identificado) & $7,12^{\mathrm{a}}$ & $6,87^{\mathrm{a}}$ & $7,00^{\mathrm{a}}$ & $7,87^{\mathrm{a}}$ & $7,12^{\mathrm{ab}}$ \\
\hline C20 (Leptosphaerulina sp.) & $7,50^{\mathrm{a}}$ & $8,62^{\mathrm{abc}}$ & $6,50^{\mathrm{a}}$ & $7,00^{\mathrm{a}}$ & $11,37^{\mathrm{ef}}$ \\
\hline C21 (Phomopsis) & $7,25^{\mathrm{a}}$ & $10,62^{\mathrm{bc}}$ & $6,87^{\mathrm{a}}$ & $7,00^{\mathrm{a}}$ & $10,67^{\mathrm{bc}}$ \\
\hline C22 (Bipolaris sp.) & $7,50^{\mathrm{a}}$ & $9,00^{\mathrm{abc}}$ & $7,75^{\mathrm{a}}$ & $8,25^{\mathrm{a}}$ & $9,87^{\mathrm{abc}}$ \\
\hline C23 (não identificado) & $8,12^{\mathrm{a}}$ & $10,66^{b c}$ & $7,50^{\mathrm{a}}$ & $7,00^{\mathrm{a}}$ & $11,12^{\text {cd }}$ \\
\hline C24 (Penicillium sp.) & $7,25^{\mathrm{a}}$ & $8,00^{\mathrm{abc}}$ & $7,00^{\mathrm{a}}$ & $6,62^{\mathrm{a}}$ & $8,75^{\mathrm{abc}}$ \\
\hline C26 (Phoma sp.) & $7,50^{\mathrm{a}}$ & $8,00^{\mathrm{abc}}$ & $8,12^{\mathrm{a}}$ & $7,67^{\mathrm{a}}$ & $9,12^{\mathrm{abc}}$ \\
\hline C28 (Trichothecium sp.) & $8,12^{\mathrm{a}}$ & $8,00^{\mathrm{abc}}$ & $7,75^{\mathrm{a}}$ & $8,00^{\mathrm{a}}$ & $7,37^{\mathrm{ab}}$ \\
\hline C29(Papulaspora sp.) & $7,62^{\mathrm{a}}$ & $6,87^{\mathrm{a}}$ & $7,12^{\mathrm{a}}$ & $7,50^{\mathrm{a}}$ & $6,50^{\mathrm{a}}$ \\
\hline C31(Fusarium sp.) & $7,50^{\mathrm{a}}$ & $7,75^{\mathrm{abc}}$ & $7,75^{\mathrm{a}}$ & $7,37^{\mathrm{a}}$ & $7,00^{\mathrm{ab}}$ \\
\hline Controle & $6,12^{\mathrm{a}}$ & $7,25^{\mathrm{a}}$ & $6,50^{\mathrm{a}}$ & $8,62^{\mathrm{ab}}$ & $7,00^{\mathrm{ab}}$ \\
\hline C.V. $(\%)$ & 9,67 & 12,85 & 10,40 & 9,09 & 15,26 \\
\hline
\end{tabular}

* médias representadas com letras diferentes indicam diferença estatística significativa pelo teste de Tukey $5 \%$ de probabilidade. 
TABELA 2: Médias dos halos de inibição $(\mathrm{cm})$ produzidos por metabólitos de fungos endofíticos isolados de soja extraídos com álcool metílico frente a bactérias patogênicas humanas

\begin{tabular}{|c|c|c|c|c|c|}
\hline Isolado & $\begin{array}{l}\text { Escherichia } \\
\text { coli }\end{array}$ & $\begin{array}{c}\text { Staphylococcus } \\
\text { aureus }\end{array}$ & $\begin{array}{c}\text { Salmonella } \\
\text { enterica }\end{array}$ & $\begin{array}{l}\text { Shigela } \\
\text { flexneri }\end{array}$ & $\begin{array}{l}\text { Micrococcus } \\
\quad \text { luteus }\end{array}$ \\
\hline C1 (Botryotrichum sp.) & $7,12^{\mathrm{abc} *}$ & $7,00^{\mathrm{abc}}$ & $7,12^{\mathrm{ab}}$ & $6,75^{\mathrm{a}}$ & $7,00^{\text {abcde }}$ \\
\hline $\mathrm{C} 2$ (Aspergillus sp.) & $9,62^{\mathrm{c}}$ & $8,25^{\mathrm{abc}}$ & $7,00^{\mathrm{ab}}$ & $8,87^{\mathrm{e}}$ & $7,62^{\text {abcde }}$ \\
\hline C4 (não identificado) & $6,50^{\mathrm{ab}}$ & $7,00^{\mathrm{abc}}$ & $7,00^{\mathrm{ab}}$ & $6,87^{\mathrm{abc}}$ & $6,75^{\text {abcde }}$ \\
\hline C7 (Nigrospora sp.) & $6,75^{\mathrm{ab}}$ & $6,75^{\mathrm{a}}$ & $7,00^{\mathrm{ab}}$ & $7,37^{\text {abcde }}$ & $7,00^{\text {abcde }}$ \\
\hline C8 (Bipolaris sp.) & $9,12^{\mathrm{bc}}$ & $8,75^{\mathrm{bc}}$ & $7,00^{\mathrm{ab}}$ & $8,12^{\text {abcde }}$ & $7,62^{\text {abcde }}$ \\
\hline C10 (Acrospeira sp.) & $6,75^{\mathrm{ab}}$ & $7,00^{\mathrm{abc}}$ & $6,50^{\mathrm{a}}$ & $6,50^{\mathrm{a}}$ & $7,12^{\text {abcde }}$ \\
\hline C11(Phomopsis sp.) & $7,00^{\mathrm{abc}}$ & $7,00^{\mathrm{abc}}$ & $7,25^{\mathrm{ab}}$ & $6,75^{\mathrm{ab}}$ & $7,37^{\text {abcde }}$ \\
\hline C12 (não identificado) & $8,62^{\mathrm{abc}}$ & $8,62^{\mathrm{abc}}$ & $7,50^{\mathrm{ab}}$ & $7,87^{\text {abcde }}$ & $8,00^{\text {abcde }}$ \\
\hline C13 (Scopulariopsis sp.) & $7,25^{\mathrm{abc}}$ & $7,12^{\mathrm{abc}}$ & $7,00^{\mathrm{ab}}$ & $6,50^{\mathrm{a}}$ & $6,50^{\mathrm{abcd}}$ \\
\hline C14 (Aspergillus sp.) & $8,37^{\mathrm{abc}}$ & $8,37^{\mathrm{abc}}$ & $8,37^{\mathrm{ab}}$ & $7,50^{\text {abcde }}$ & $7,75^{\text {abcde }}$ \\
\hline C16 (Aspergillus sp.) & $7,00^{\mathrm{abc}}$ & $7,00^{\mathrm{abc}}$ & $6,50^{\mathrm{a}}$ & $7,00^{\mathrm{abcd}}$ & $6,75^{\text {abcde }}$ \\
\hline C17 (Mucor sp.) & $8,87^{\mathrm{abc}}$ & $8,00^{\mathrm{abc}}$ & $8,87^{\mathrm{ab}}$ & $8,25^{\text {abcde }}$ & $8,50^{\text {bcde }}$ \\
\hline C18 (Alternaria sp.) & $7,00^{\mathrm{abc}}$ & $6,75^{\mathrm{a}}$ & $7,12^{a b}$ & $7,00^{\mathrm{abcd}}$ & $6,00^{\mathrm{a}}$ \\
\hline C19 (não identificado) & $6,50^{\mathrm{ab}}$ & $7,12^{\text {abc }}$ & $6,50^{\mathrm{a}}$ & $7,12^{\text {abcde }}$ & $6,12^{\mathrm{ab}}$ \\
\hline C20 (Leptosphaerulina sp.) & $7,50^{\mathrm{abc}}$ & $8,00^{\mathrm{abc}}$ & $8,37^{\mathrm{ab}}$ & $8,50^{\text {bcde }}$ & $8,12^{\text {abcde }}$ \\
\hline C21 (Phomopsis) & $7,75^{\mathrm{abc}}$ & $8,50^{\mathrm{abc}}$ & $8,50^{\mathrm{ab}}$ & $7,50^{\text {abcde }}$ & $8,62^{\text {cde }}$ \\
\hline C22 (Bipolaris sp.) & $7,62^{\mathrm{abc}}$ & $8,87^{\mathrm{c}}$ & $9,12^{\mathrm{b}}$ & $8,25^{\text {abcde }}$ & $8,75^{\mathrm{de}}$ \\
\hline C23 (não identificado) & $6,87^{\mathrm{abc}}$ & $8,75^{\mathrm{bc}}$ & $8,87^{\mathrm{ab}}$ & $8,75^{\mathrm{de}}$ & $8,87^{\text {de }}$ \\
\hline C24 (Penicillium sp.) & $6,62^{\mathrm{abc}}$ & $8,25^{\mathrm{abc}}$ & $8,25^{\mathrm{ab}}$ & $8,62^{\text {cde }}$ & $9,00^{\mathrm{e}}$ \\
\hline C26 (Phoma sp.) & $7,00^{\mathrm{abc}}$ & $8,25^{\mathrm{abc}}$ & $8,12^{\mathrm{ab}}$ & $8,75^{\mathrm{de}}$ & $8,50^{\text {bcde }}$ \\
\hline C28 (Trichothecium sp.) & $6,25^{\mathrm{a}}$ & $7,00^{\mathrm{abc}}$ & $6,62^{\mathrm{a}}$ & $7,00^{\text {abcd }}$ & $6,25^{\mathrm{abc}}$ \\
\hline C29(Papulaspora sp.) & $7,12^{\mathrm{abc}}$ & $7,00^{\mathrm{abc}}$ & $7,00^{\mathrm{ab}}$ & $7,25^{\text {abcde }}$ & $6,12^{\mathrm{ab}}$ \\
\hline C31(Fusarium sp.) & $6,75^{\mathrm{abc}}$ & $6,87^{\mathrm{ab}}$ & $7,12^{\mathrm{ab}}$ & $7,00^{\mathrm{abcd}}$ & $6,00^{\mathrm{a}}$ \\
\hline Controle & $7,75^{\mathrm{abc}}$ & $7,62^{\mathrm{abc}}$ & $7,00^{\mathrm{ab}}$ & $8,25^{\text {abcde }}$ & $8,25^{\text {abcde }}$ \\
\hline C.V. $(\%)$ & 11,63 & 8,09 & 10,38 & 7,74 & 10,31 \\
\hline
\end{tabular}

Dentre os isolados avaliados, C12 (não identificado) e C20 (Leptosphaerulina sp.) apresentaram eficiência contra pelo menos uma bactéria testada, quando os metabólitos foram obtidos com os diferentes tipos de solventes. Isso pode indicar uma maior diversidade em relação aos tipos de compostos antimicrobianos produzidos por estes isolados. Quando são comparados todos os isolados, além de $\mathrm{C} 12$ e C20, os isolados C21 (Phomopsis sp.) e C23 (não identificado), apresentaram atividade antimicrobiana contra mais de uma bactéria testada. Torres et al. (2008) buscaram avaliar três espécies: Leonotis nepetifolia (L.) R. Br., Leonurus sibiricus L. e Leucas martinicensis (Jacq.) R. Br. pertencentes à família Lamiaceae, popularmente conhecidas como Cordão-de-Frade. A melhor atividade antimicrobiana entre os extratos hidroalcoólico, metanólico, hexânico e em acetato de etila, sobre C. albicans, $M$. luteus, S. aureus e E. coli foi obtida com os extratos hidroalcóolicos. 
TABELA 3: Médias dos halos de inibição $(\mathrm{cm})$ produzidos por metabólitos de fungos endofíticos isolados de soja em meio fermentado frente a bactérias patogênicas humanas

\begin{tabular}{|c|c|c|c|c|c|}
\hline Isolado & $\begin{array}{c}\text { Escherichia } \\
\text { coli }\end{array}$ & $\begin{array}{l}\text { Staphylococcus } \\
\text { aureus }\end{array}$ & $\begin{array}{c}\text { Salmonella } \\
\text { enterica }\end{array}$ & $\begin{array}{l}\text { Shigela } \\
\text { flexneri }\end{array}$ & $\begin{array}{r}\text { Micrococcus } \\
\text { luteus }\end{array}$ \\
\hline C1 (Botryotrichum sp.) & $6,50^{\mathrm{a} *}$ & $7,12^{\mathrm{a}}$ & $7,12^{\mathrm{ab}}$ & $6,62^{\mathrm{a}}$ & $7,00^{\mathrm{a}}$ \\
\hline C2 (Aspergillus sp.) & $7,87^{\mathrm{abc}}$ & $7,12^{\mathrm{a}}$ & $7,87^{\mathrm{abc}}$ & $9,37^{\mathrm{b}}$ & $8,00^{\mathrm{ab}}$ \\
\hline C4 (não identificado) & $7,25^{\mathrm{abc}}$ & $7,00^{\mathrm{a}}$ & $7,00^{\mathrm{a}}$ & $7,00^{\mathrm{ab}}$ & $7,37^{\mathrm{ab}}$ \\
\hline C7 (Nigrospora sp.) & $7,12^{\mathrm{abc}}$ & $7,12^{\mathrm{a}}$ & $7,00^{\mathrm{a}}$ & $7,00^{\mathrm{ab}}$ & $7,00^{\mathrm{a}}$ \\
\hline C8 (Bipolaris sp.) & $7,75^{\mathrm{abc}}$ & $7,50^{\mathrm{a}}$ & $8,25^{\mathrm{abc}}$ & $8,12^{\mathrm{ab}}$ & $9,12^{\mathrm{abc}}$ \\
\hline C10 (Acrospeira sp.) & $7,00^{\mathrm{abc}}$ & $7,00^{\mathrm{a}}$ & $7,00^{\mathrm{a}}$ & $7,00^{\mathrm{ab}}$ & $7,25^{\mathrm{ab}}$ \\
\hline C11(Phomopsis sp.) & $6,75^{\mathrm{ab}}$ & $7,37^{\mathrm{a}}$ & $7,12^{\mathrm{ab}}$ & $7,00^{\mathrm{ab}}$ & $7,00^{\mathrm{a}}$ \\
\hline C12 (não identificado) & $8,12^{\mathrm{abc}}$ & $7,50^{\mathrm{a}}$ & $7,62^{\mathrm{abc}}$ & $8,12^{\mathrm{ab}}$ & $10,87^{\mathrm{c}}$ \\
\hline C13 (Scopulariopsis sp.) & $6,87^{\mathrm{abc}}$ & $7,12^{\mathrm{a}}$ & $7,37^{\mathrm{abc}}$ & $7,12^{\mathrm{ab}}$ & $7,25^{\mathrm{ab}}$ \\
\hline C14 (Aspergillus sp.) & $7,75^{\mathrm{abc}}$ & $8,00^{\mathrm{a}}$ & $8,75^{\mathrm{c}}$ & $8,12^{\mathrm{ab}}$ & $8,50^{\mathrm{abc}}$ \\
\hline C16 (Aspergillus sp.) & $6,50^{\mathrm{abc}}$ & $7,12^{\mathrm{a}}$ & $7,12^{\mathrm{ab}}$ & $7,00^{\mathrm{ab}}$ & $6,75^{\mathrm{a}}$ \\
\hline C17 (Mucor sp.) & $8,50^{\mathrm{c}}$ & $8,00^{\mathrm{a}}$ & $8,37^{\mathrm{abc}}$ & $8,75^{\mathrm{ab}}$ & $8,25^{\mathrm{abc}}$ \\
\hline C18 (Alternaria sp.) & $7,25^{\mathrm{abc}}$ & $7,25^{\mathrm{a}}$ & $7,25^{\mathrm{abc}}$ & $7,00^{\mathrm{ab}}$ & $6,87^{\mathrm{a}}$ \\
\hline C19 (não identificado) & $7,50^{\mathrm{abc}}$ & $7,00^{\mathrm{a}}$ & $7,00^{\mathrm{a}}$ & $7,00^{\mathrm{ab}}$ & $6,87^{\mathrm{a}}$ \\
\hline C20 (Leptosphaerulina sp.) & $7,75^{\mathrm{abc}}$ & $7,00^{\mathrm{a}}$ & $8,62^{\mathrm{bc}}$ & $8,12^{\mathrm{ab}}$ & $10,00^{\mathrm{bc}}$ \\
\hline C21 (Phomopsis) & $7,50^{\mathrm{abc}}$ & $7,25^{\mathrm{a}}$ & $7,87^{\mathrm{abc}}$ & $8,00^{\mathrm{ab}}$ & $8,00^{\mathrm{ab}}$ \\
\hline C22 (Bipolaris sp.) & $8,37^{\mathrm{bc}}$ & $7,00^{\mathrm{a}}$ & $8,00^{\mathrm{abc}}$ & $8,25^{\mathrm{ab}}$ & $8,00^{\mathrm{ab}}$ \\
\hline C23 (não identificado) & $7,12^{\mathrm{abc}}$ & $7,00^{\mathrm{a}}$ & $7,62^{\mathrm{abc}}$ & $8,12^{\mathrm{ab}}$ & $9,00^{\mathrm{abc}}$ \\
\hline C24 (Penicillium sp.) & $7,37^{\mathrm{abc}}$ & $7,50^{\mathrm{a}}$ & $7,37^{\mathrm{abc}}$ & $8,25^{\mathrm{ab}}$ & $8,37^{\mathrm{abc}}$ \\
\hline C26 (Phoma sp.) & $8,00^{\mathrm{abc}}$ & $7,12^{\mathrm{a}}$ & $7,75^{\mathrm{abc}}$ & $8,00^{\mathrm{ab}}$ & $8,00^{\mathrm{ab}}$ \\
\hline C28 (Trichothecium sp.) & $7,12^{\mathrm{abc}}$ & $7,00^{\mathrm{a}}$ & $7,00^{\mathrm{a}}$ & $7,00^{\mathrm{ab}}$ & $6,50^{\mathrm{a}}$ \\
\hline C29(Papulaspora sp.) & $7,00^{\mathrm{abc}}$ & $7,12^{\mathrm{a}}$ & $7,00^{\mathrm{a}}$ & $6,87^{\mathrm{ab}}$ & $7,00^{\mathrm{a}}$ \\
\hline C31(Fusarium sp.) & $7,00^{\mathrm{abc}}$ & $7,12^{\mathrm{a}}$ & $7,12^{\mathrm{ab}}$ & $6,87^{\mathrm{ab}}$ & $7,37^{\mathrm{ab}}$ \\
\hline Controle & $7,00^{\mathrm{abc}}$ & $7,00^{\mathrm{a}}$ & $7,12^{\mathrm{ab}}$ & $6,41^{\mathrm{a}}$ & $6,75^{\mathrm{a}}$ \\
\hline C.V. $(\%)$ & 7,51 & 6,92 & 6,51 & 11,25 & 11,33 \\
\hline
\end{tabular}

* médias representadas com letras diferentes indicam diferença estatística significativa pelo teste de Tukey $5 \%$ de probabilidade.

Entretanto, em nosso trabalho, foi obsevada melhor ação dos extratos em acetato de etila, com nove resultados de atividade antimicrobiana superiores ao controle, seguido de cinco com meio fermentado e nenhum com metanol (Tabelas 1, 2 e 3). Essa atividade antimicrobiana, conforme observada também por Santos \& Minguzzi (2010), provavelmente é devida a certos grupos de compostos fenólicos que são melhores extraídos pelo acetato de etila. O acetato é um solvente apolar separando diferentes grupos de metabólitos através de sua polaridade, sendo que os principais metabólitos secundários presentes em plantas, obtidos em acetato, são os flavonóides, taninos, xantonas, ácidos triterpênicos, saponinas e compostos fenólicos em geral (MIGUEL et al., 1996). Além disso, já foi possível isolar também com este solvente os flavonóides quercetina e rutina, que apresentaram relevante ação analgésica, além do galato de etila, composto fenólico que também exerce efeito analgésico (MIGUEL et al., 1995).

Orlandelli et al. (2012) avaliaram a ação antibacteriana de metabólitos secundários produzidos por quatro fungos endofíticos isolados da planta Piper hispidum Sw. (falsojaborandi), um fungo da espécie Lasiodiplodia theobromae (Pat.) Griffon \& Maubl. 1909, um pertencente a ordem Diaporthales e dois isolados não identificados, extraídos com acetato de etila contra $S$. aureus, sendo que todos os metabólitos testados apresentaram ação contra a bactéria, e o isolado. L. theobromae, com maior atividade antimicrobiana, o que corrobora com o presente trabalho em que somente o extrato obtido a partir do acetato de etila apresentou atividade antimicrobiana contra $S$. aureus. 
Gomes-Figueiredo et al. (2007) isolaram fungos endofíticos de espinheira-santa e de 30 fungos avaliados quanto a atividade antimicrobiana, apenas dois isolados apresentaram atividade contra E. coli, M. luteus, Klebsiella pneumoniae (Schroeter 1886) Trevisan 1887 e $S$. aureus, diferindo de nossos resultados, quando comparados quantitativamente aos isolados de fungos endofíticos de soja com potencial antimicrobiano. Deve-se destacar, porém, que nenhum dos metabólitos apresentou atividade antimicrobiana contra E. coli.

Garcia et al. (2012) encontraram resultados muito semelhantes aos do presente trabalho, em que metabólitos de fungos endofíticos isolados da planta medicinal Sapindus saponaria L. apresentaram maior atividade antimicrobiana quando obtidos em acetato de etila e diretamente do meio fermentado, contra as bactérias E. coli, S. aureus, Salmonella typhi (Schroeter 1886) Warren and Scott 1930, M. luteus e Enterococcus hirae Farrow and Collins 1985, não apresentando atividade antimicrobiana quando obtidos de metanol.

Quanto às atividades enzimáticas dos fungos endofíticos de folhas de soja, nenhum dos 24 isolados apresentou atividade lipolítica. Quanto à atividade proteolítica, 12,5\% foram capazes de degradar proteína e 83,3\% dos fungos apresentaram atividade amilolítica, com produção de halos de degradação do amido (Tabela 4).

TABELA 4: Atividade enzimática de fungos endofíticos isolados de soja

\begin{tabular}{lccc}
\hline \multicolumn{1}{c}{ Fungo endofítico } & Lipase & Protease & Amilase \\
\hline C1 (Botryotrichum sp.) & - & - & + \\
C2 (Aspergillus sp.) & - & - & + \\
C3 (Phoma sp.) & - & - & - \\
C4 (não identificado) & - & - & + \\
C5 (Nectria sp.) & - & - & + \\
C6 (Leptosphaerulina sp.) & - & + & + \\
C7 (Nigrospora sp.) & - & - & + \\
C8 (Bipolaris sp.) & - & - & - \\
C10 (Acrospeira sp.) & - & + & + \\
C11 (Phomopsis sp.) & - & + & + \\
C13 (Scopulariopsis sp.) & - & - & + \\
C14 (Aspergillus sp.) & - & - & + \\
C15 (Aspergillus sp.) & - & - & - \\
C16 (Aspergillus sp.) & - & - & + \\
C18 (Alternaria sp.) & - & - & - \\
C20 (Leptosphaerulina sp.) & - & - & + \\
C21 (Phomopsis sp.) & - & - & + \\
C23 (não identificado) & - & - & + \\
C24 (Penicillium sp.) & - & - & + \\
C26 (Phoma sp.) & - & - & + \\
C28 (Trichothecium sp.) & - & - & + \\
C29 (Papulaspora sp.) & - & - & + \\
C31 (Fusarium sp.) & - & - & + \\
C32 (Aspergillus sp.) & - & - & + \\
\hline
\end{tabular}

*(+) Presença de atividade enzimática. (-) Ausência de atividade enzimática.

(Figura 1).

A atividade de amilase foi a mais evidente e presente na grande maioria dos fungos 


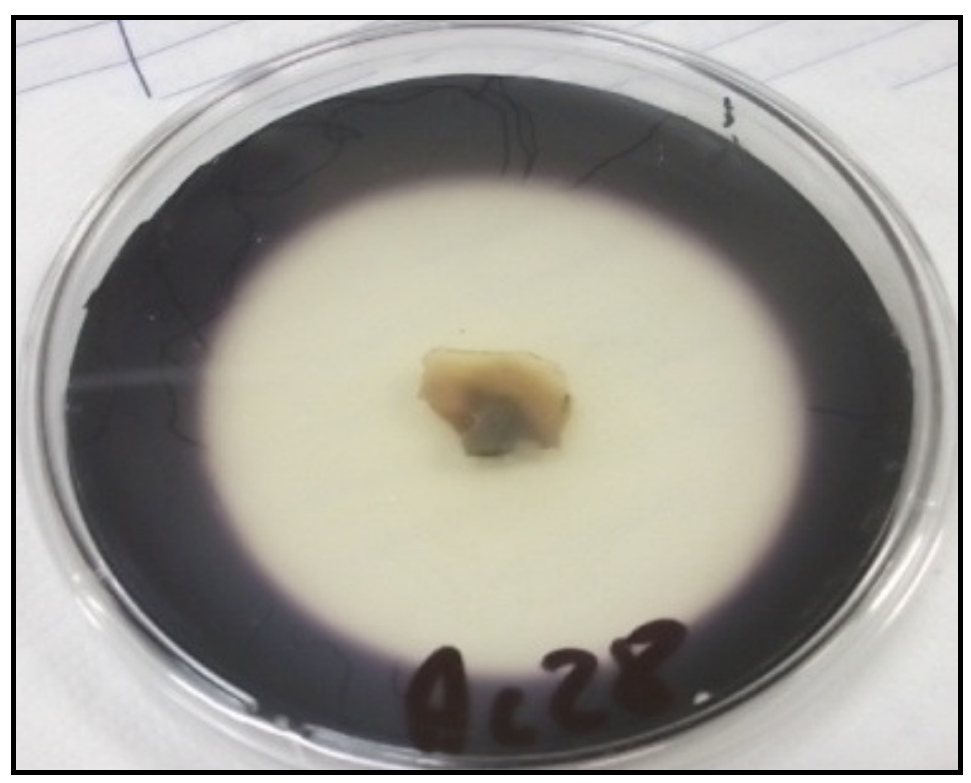

FIGURA 1: Halo de degradação de amido, evidenciado com lugol e caracterizado como atividade da amilase do fungo endofítico Trichothecium sp. isolado de folha de soja.

Os resultados para produção de amilases contrastam com os obtidos por Silva et al. (2006), em que fungos endofíticos isolados de pinha não apresentaram atividades amilolíticas, enquanto que neste trabalho foi a enzima mais produzida.

Choi et al. (2005) obtiveram resultados semelhantes quanto a atividade amilolítica testando endofíticos isolados de Brucea javanica (L.) Merr. A utilização ampla destas enzimas é reflexo da elevada especificidade de sua ação biocatalisadoras. Porém, enzimas com o mesmo perfil de atuação sob o substrato, podem apresentar funcionamento ótimo em $\mathrm{pH}$, temperatura e concentração iônica diferentes, o que requer a seleção daquelas adequadas às condições nas quais serão utilizadas.

Em relação à produção de lipases, os fungos podem apresentar maior dificuldade de degradação de alguns tipos de ácidos graxos e ainda o meio de cultura pode ter inteferido na ausência de atividade lipolítica, conforme observado por Tomiya e Motta (2009). Estes autores, testando a atividade enzimática de fungos endofíticos isolados de diferentes espécies de plantas verificaram que esta foi a menor atividade enzimática apresentada pelos fungos em relação a produção das enzimas celulases e xilanases. Zaferanloo et al. (2013) também observaram que a produção de enzimas extracelulares por fungos endofíticos isolados de Eremophila longifolia (R. Br.) F. Muell., uma planta nativa da Austrália, variou de acordo com as condições do meio de cultivo, sendo que cada enzima necessita de um $\mathrm{pH}$ e temperatura diferentes para serem produzidas. A metodologia utilizada para avaliação da atividade lipolítica (Hankin \& Anagnostakis, 1975) é uma das mais citadas na literatura e também foi reproduzida por Maria et al. (2005) para avaliação da atividade lipolítica de fungos endofíticos de Acanthus ilicifolius L. e Acrostichum aureum L., plantas de mangue da Índia, no qual os sete endófitos avaliados apresentaram atividade lipolítica.

Para os isolados que apresentaram atividade enzimática (Tabela 4) foi realizado o cálculo da atividade enzimática, (Pz) (Tabela 5). 
TABELA 5: Atividade enzimática $(\mathrm{Pz})$ de 20 fungos endofíticos isolados de soja (Glycine $\max )$

\begin{tabular}{|c|c|c|c|c|}
\hline \multirow{2}{*}{ Isolado } & \multicolumn{2}{|c|}{ Amilolítica } & \multicolumn{2}{|c|}{ Proteolítica } \\
\hline & $\mathrm{Pz}$ & Classe & $\mathrm{Pz}^{*}$ & Classe* \\
\hline C1 (Botryotrichum sp.) & 0,22 & 3 & - & - \\
\hline C2 (Aspergillus sp.) & 1,00 & 1 & - & - \\
\hline C4 (não identificado) & 1,00 & 1 & - & - \\
\hline C5 (Nectria sp.) & 0,15 & 3 & - & - \\
\hline C6 (Leptosphaerulina sp.) & 0,37 & 3 & 0,66 & 2 \\
\hline C7 (Nigrospora sp.) & 0,62 & 3 & - & - \\
\hline C10 (Acrospeira sp.) & 0,89 & 2 & 0,58 & 3 \\
\hline C11 (Phomopsis sp.) & 0,39 & 3 & 0,74 & 2 \\
\hline C13 (Scopulariopsis sp.) & 0,53 & 3 & - & - \\
\hline C14 (Aspergillus sp.) & 0,56 & 1 & - & - \\
\hline C16 (Aspergillus sp.) & 1,00 & 1 & - & - \\
\hline C20 (Leptosphaerulina sp.) & 0,56 & 3 & - & - \\
\hline C21 (Phomopsis sp.) & 1,00 & 1 & - & - \\
\hline C23 (não identificado) & 1,00 & 1 & - & - \\
\hline C24 (Penicillium sp.) & 1,00 & 1 & - & - \\
\hline C26 (Phoma sp.) & 0,41 & 3 & - & - \\
\hline C28 (Trichothecium sp.) & 1,00 & 1 & - & - \\
\hline C29 (Papulaspora sp.) & 1,00 & 1 & - & - \\
\hline C31 (Fusarium sp.) & 0,86 & 2 & - & - \\
\hline C32 (Aspergillus sp.) & 0,28 & 3 & - & - \\
\hline
\end{tabular}

Os maiores índices de atividade amilolítica foram apresentados pelos isolados $\mathrm{C} 1$ (Botryotrichum sp.), C5 (Nectria sp.), C6 (Leptosphaerulina sp.), C7 (Nigrospora sp.), C11 (Phomopsis sp.), C13 (Scopulariopsis sp.), C20 (Leptosphaerulina sp.), C26 (Phoma sp.) e C32 (Aspergillus sp.), que pertencem a classe 3, o que indica atividade enzimática fortemente positiva. Para a atividade proteolítica destaca-se o isolado C10 (Acrospeira), também pertencente a classe 3 . Os fungos endofíticos que apresentaram atividade enzimática para amilases e proteases foram C6 (Leptosphaerulina sp.), C10 (Acrospeira sp.) e C11 (Phomopsis sp.), que embora não sejam relatados como os maiores produtores destas enzimas, apresentaram-se como positivos e fortemente positivos para ambas as enzimas, 0 que indica que estes fungos podem ser promissores como produtores de amilases e proteases.

Índices enzimáticos semalhantes foram obtidos por Cuzzi et al. (2011), em que fungos endofíticos isolados de Baccharis dracunculifolia DC., apresentaram índices enzimáticos semelhantes aos do presente trabalho, com isolados dos gêneros Scopulariopsis e Aspergillus apresentando em ambos os trabalhos índices positivos e fortemente positivos para a enzima amilase. Em estudo semelhante, Sunitha et al. (2013), avaliaram a atividade enzimática de 50 fungos endofíticos isolados das plantas medicinais Alpinia calcarata Roscoe, Bixa orellana L., Calophyllum inophyllum L. e Catharanthus roseus (L.) G. Don, apresentando resultados contrastantes aos do presente trabalho, em que os gêneros Nigrospora, Phomopsis e Phoma não apresentaram atividade amilolítica. Entretanto, os dois trabalhos se assemelham ao demonstrarem que diferentes isolados do gênero Aspergillus podem apresentar atividade enzimática alta ou nula (Tabela 5). Embora haja relatos na literatura de fungos do gênero Aspergillus serem grandes produtores de lipases, proteases e amilases (ORLANDELLI et al., 2012b), a variação na produção de enzimas pode ser dependente da espécie ou do isolado.

Persp. online: biol. \& saúde, Campos dos Goytacazes, 9 (3), 01-15, 2013 


\section{CONCLUSÕES}

Foi possível verificar que nove fungos endofíticos isolados de folhas de soja (Glycine max) apresentaram atividades antimicrobiana contra pelo menos uma bactéria patogênica a humanos, indicando uma possível potencialidade no controle desses organismos.

A atividade amilolítica foi evidente para 83,3\%, com menor frequência de atividade proteolítica, cerca de $12,5 \%$ dos isolados, e ausência de produção de lipases por todos os fungos. A forte atividade enzimática apresentada por 10 isolados indica o potencial destes fungos para utilização na degradação de substâncias oriundas de atividades industriais.

\section{REFERÊNCIAS}

ARNOLD, A.E.; MEJIA, L.C.; KYLLO, D.; ROJAS, E.I.; MAYNARD, Z.; ROBBINS, N.; HERRE, E.A. Fungal endophytes limit pathogen damage in Tropical tree. Proceedings of the National Academy of Sciences, v.26, p.15649-15654, 2003.

AZEVEDO, J.L.; BARROS, N.M.; SERAFINI, L.A. Biotecnologia: avanços na agricultura e na agroindústria. Caxias do Sul: EDUCS, 2002, Caxias do Sul - RS, Brasil.

BERNARDI-WENZEL, J.; GARCIA, A.; RUBIN FILHO, C.J.; PRIOLI, A.J.; PAMPHILE, J.A. Evaluation of foliar fungal endophyte diversity and colonization of medicinal plant Luehea divaricata (Martius e Zuccarini). Biological Research, v.43, p. 375-384, 2010.

BERNARDI-WENZEL, J.; SIQUEIRA, A.L.; BURIN, F.A.G.; HEIN, D.P.R.; SILVEIRA, J.A.; ROMANI, S. Isolamento e atividade antagonística de fungos endofíticos isolados de soja (Glycine max L. (Merril)). SaBios: Revista de Saúde e Biologia, v.7, n.3, p.86-96, set.-dez., 2012.

BEYNON, R.J.; BOND, J.S. Proteolytic enzymes: A practical approach. Oxford University Press, Oxford. 1989.

BIER, M. Lipases: Methods in Enzymology, New York, v. 1, p. 627-642, 1955.

BLODGETT J.T., SWART, W.J., LOUW, S.VDM.; WEEKS, W.J. Soil amendments and watering influence the incidence of endophytic fungi in Amaranthus hybridus in South Africa. Applied Soil Ecology, v. 35, p. 311-318, 2007.

CARROL, G.C., CARROLL, F.E. Studies on the incidence of coniferous needle Endophytes in the Pacitfic Northwest. Canadian Jornal of Botany, v.56, p.3034-3043, 1978.

CHAPLA, V.M.; BIASETTO, C.R.; ARAÚJO, A.R. Fungos Endofíticos: Uma Fonte Inexplorada e Sustentável de Novos e Bioativos Produtos Naturais. Revista Virtual Química, (no prelo). Data de publicação na Web: 11 de novembro de 2012.

CHOI, Y.W., HODGKISS, I.J., HYDE, K.D.Enzyme production by endophytes of Brucea javanica. Journal of Agricultural Technology, v. 1, p.55-66, 2005.

CUNHA, I.G.B.; SOBRINHO, T.J.S.T.; SILVA, R.E.A.; AMORIN, E.L.C.; ARAÚJO, J.M. Influência do meio de cultura na produção de metabólitos bioativos do endófito Streptomyces sp. EBR49-A UFPEDA. Revista Brasileira de Farmácia, v. 90, n. 2, p. 120-123, 2009.

CUZZI, C.; LINK, S.; VILANI, A.; ONOFRE, S.B. Enzimas extracelulares produzidas por fungos endofíticos isolados de Baccharis Dracunculifolia D.C. (ASTERAECEAE). Global Science and Technology, v. 04, n. 02, p.47 - 57, mai/ago. 2011.

EMBRAPA/SOJA: http://www.cnpso.embrapa.br/index.php?op_page=22\&cod_pai=16 . Acesso em 31/05/2013.

ESPOSITO, E; AZEVEDO, J. L. Fungos: uma introdução à biologia, bioquímica e biotecnologia. Caxias do Sul: EDUCS, 2004. 
FERREIRA, D.F. Análises estatísticas por meio do SISVAR para Windows versão 4.0. In: $\mathbf{4 5}^{\mathbf{a}}$ Reunião Anual da Região Brasileira da Sociedade Internacional de Biometria, UFSCar, São Carlos, SP, 2000. p. 255-258.

FIRÁKOVÁ; ŠTURDÍKOVÁ; MÚCKOVÁ. Bioactive secondary metabolites produced by microorganisms associated with plants, Versita, v. 62, n. 3, p. 251-257, 2007.

FOUKIS, A.; STERGIOUA, P.Y.; THEODOROUA, L.G.; PAPAGIANNI, M.; PAPAMICHAEL, E.M. Purification, kinetic characterization and properties of a novel thermo-tolerant extracellular protease from Kluyveromyces marxianus IFO 0288 with potential biotechnological interest. Bioresource Technology, v. 123, p. 214-220, 2012.

GARCIA, A.; RHODEN, S.A.; BERNARDI-WENZEL, J.; ORLANDELLI, R.C.; AZEVEDO, J.L.; PAMPHILE, J.A. Antimicrobial Activity of Crude Extracts of Endophytic Fungi Isolated from Medicinal Plant Sapindus saponaria L. Journal of Applied Pharmaceutical Science, v. 2, n. 10, p. 35-40, out., 2012.

GOMES-FIGUEIREDO, J. et al. Bioprospecting highly diverse endophytic Pestalotiopsis spp. with antibacterial properties from Maytenus ilicifolia, a medicinal plant from Brazil. Canadian Journal of Microbiology, v. 53, p. 1123-1132, 2007.

GUPTA, R.; RATHI, P.; GUPTA, N.; BRADOO, S. Lipase assays for conventional and molecular screening: an overview. Biotechnology and Applied Biochemistry, v. 37, p. 63-71, 2003.

HANKIN, L.; ANAGNOSTAKIS, S. G. The use of solid media for detection of enzyme production by fungi. Mycology, v. 67, p.597-607, 1975.

LI, H.; QING, C.; ZHANG, Y., ZHAO, Z. Screening for endophytic fungi with antitumour and antifungal activities from Chinese medicinal plants. World Journal of Microbiology and Biotechnology, v.21, p.1515-1519, 2005.

MARIA, G.L.; SRIDHAR, K.R.; RAVIRAJA, N.S. Antimicrobial and enzyme activity of mangrove endophytic fungi of southwest coast of India. Journal of Agricultural Technology, v.1, p.67-80, 2005.

MARINHO, A.M.R.; MARINHO, P.S.B.; RODRIGUES FILHO, E. Esteroides produzidos por Penicillium herquei, um fungos endofítico isolado dos frutos de Melia azedarach (MELIACEAE).

Química Nova, v. 32, n. 7, p.1710-1712, 2009.

MESSIAS, J.M.; COSTA, B.Z.; LIMA, V.M.G.; GIESE, E.C.; DEKKER, R.F.H., BARBOSA, A.M. Lipases microbianas: Produção, propriedades e aplicações biotecnológicas. Semina: Ciências Exatas e Tecnológicas, Londrina, v. 32, n. 2, p. 213-234, 2011.

MIGUEL, O.G.; CECHINEL FILHO, V.; PIZZOLATTI, M.G.; SANTOS, A.R.S.; CALIXTO, J.B.; FERRARI, F.; MESSANA, I.; YUNES, R.A. A Triterpene and Phenolic Compounds from Leaves and Stems of Phyllanthus sellowianus. Planta Medica, v. 61, p. 391, 1995.

MIGUEL, O.G.; CALIXTO, J.B.; SANTOS, A.R.S.; MESSANA, I.; FERRARI, F.; CECHINEL FILHO, V.; PIZZOLATTI, M.G.; YUNES, R.A. Chemical and Preliminary Analgesic Evaluation of Geraniin and Furosin Isolated from Phyllanthus sellowianus. Planta Medica, v. 62, p. 146, 1996.

ORLANDELLI, R.C.; ALBERTO, R.N.; ALMEIDA, T.T.; AZEVEDO, J.L.; PAMPHILE, J.A. In vitro Antibacterial Activity of Crude Extracts Produced by Endophytic Fungi Isolated from Piper hispidum Sw. Journal of Applied Pharmaceutical Science, v.2, n.10, p.137-141, 2012a.

ORLANDELLI, R.C.; SPECIAN, V.; FELBER, A.C.; PAMPHILE, J.A. Enzimas de interesse industrial: produção por fungos e aplicações. SaBios: Revista de Saúde e Biologia, v.7, n.3, p.97-109, set.-dez., 2012b.

PAMPHILE, J.A.; AZEVEDO, J.L. Molecular characterization of endophytic strains of Fusarium verticillioides (Fusarium moniliforme) from maize (Zea mays.L). World Journal of Microbiology and Biotechnology, v.18, n.5, p.391 - 396, 2002. 
PEIXOTO-NETO, P.A.S., AZEVEDO, J.L., ARAÚJO, W.L. Microrganismos endofíticos. Biotecnoliga Ciência \& Desenvolvimento, v.29, p.62-76, 2002.

PONTECORVO, G.; ROPER, J.A.; HEMMONS, L.M.; MACDONALD, K.D.; BUFTON, A.W.J. The genetics of Aspergillus nidulans. Advanced in genetics, v.5, p.141-238, 1953.

SAIKKONEN, K.; WÄLI, P.; HELANDER, M.; FAETH, S.H. Evolution of endophyte-plant symbioses. Trends in Plant Science, v.9, n.6, p.275-280, 2004.

SAMBROOK, J.; RUSSEL, D.W. Molecular cloning: A laboratory manual. 3. ed. Cold Spring Harbor Laboratory Press, New York. 2001.

SANTOS, C.R.Z; MINGUZZI, S. Estudo Químico das Sementes e Frutos da Jatropha gossypifolia L. $13^{\circ}$ workshop de plantas medicinais. In: Anais do $\mathbf{1 3}^{\circ}$ workshop de plantas medicinais. UFGD, 2010.

SELLAMI-KAMOUN, A.; HADDAR, A.; ALI, N.E.H.; GHORBEL-FRINKA, B.; KANOUN, S.; NASRI, M. Stability of thermostable alkaline protease from Bacillus licheniformis RP1 in commercial solid laundry detergent formulations. Microbiological Research, v. 163, p. 299-306, 2008.

SETTE, L.D.; PASSARINI, M.R.Z.; DELAMELINA, C.; SALATI, F.; DUARTE, M.C.T. Molecular characterization and antimicrobial activity of endophytic fungi from coffee plants. World Journal of Microbiology and Biotechnology, v.22, p.1185-1195, 2006.

SILVA, G.H.; OLIVEIRA, D.F.; CAMPOS, V.P. Purificação de metabólitos fúngicos com efeitos tóxicos sobre Meloidogyne incognita. Fitopatologia brasileira, v. 27, n.6, p.594-598, 2002.

SILVA, R. L.O.; LUZ, J.L.; SILVEIRA, E.B.; CAVALCANTE, U.M.T. Fungos endofíticos em Annona spp.: isolamento, caracterização enzimática e promoção do crescimento em mudas de pinha. Acta botanica Brasílica, v. 20, n. 03, p. 649-655, 2006.

SMITH, D.; ONIONS, A.H.S. The preservation and maintenance of living fungi. Page Bros, Norwick. 1983.

SOUZA A.Q.L.; SOUZA, A.F.L.; ALTOLFI FILHO, E.; BELÉM PINHEIRO, M.L.; SARQUIS, M.I.M.; PEREIRA, J. O. Atividade antimicrobiana de fungos endofíticos isolados de plantas tóxicas da amazônia: Palicourea longiflora (aubl.) rich e Strychnos cogens bentham. Acta amazônica, v.34, n.2, p.185-195, 2004.

STROBEL, G. Endophytes as sources of bioactive products. Microbes and Infection, v. 5, p. 535544,2003

STROBEL G.A.; DAISY, B. Bioprospecting for microbial endophytes and their natural products. Microbiology and Molecular Biology Reviews, v.67, n.4, p.491-502, 2003.

SUNITHA, V.H; NIRMALA DEVI, D.; SRINIVAS C. Extracellular enzymatic activity of endophytic fungal strains isolated from medicinal plants. World Journal of Agricultural Sciences, v.9, n.1,p.0109, 2013.

TOMIYA, P.E.O.; MOTTA, C.M.S. Detecção da capacidade de produção de enzimas por fungos endofíticos. In: Anais do XVII Congresso de Iniciação Científica I Congresso de Iniciação em Desenvolvimento Tecnológico e Inovação. Universidade Federal de Pernambuco, 2009.

TORRES, E.C.; RIBEIRO, A.; SOARES, M.A. Abordagem Fitoquímica e prospecção do potencial antimicrobiano in vitro das partes aéreas de três espécies vegetais pertencentes à família Lamiaceae. Fundação Comunitária de Ensino Superior de Itabira, 2008. Disponível em: httpwww.diaadiaeducacao.pr.gov.brdiaadiadiadiaarquivosFileconteudoartigos_tesesBiologiaArti/gosa bordagem-fitoquimica.pdf. Acesso em: 09/10/2012.

WANG, F.W.; JIAO,R. H.;CHENG, A.B.; TAN, S.H.; SONG,Y. C. Antimicrobial potentials of endophytic fungi residing in Quercus variabilis and brefeldin A obtained from Cladosporium sp. World Journal of Microbiology and Biotechnology, v. 23, p.79-83, 2007.

WIT, J. N. The use of whey protein products: a review. NIZO Research Report, v. 281, 1989, 23p. 
ZAFERANLOO, B.; VIRKAR, A.; MAHON, P.J.; PALOMBO, E.A. Endophytes from an Australian native plant are a promising source of industrially useful enzymes. World Journal of Microbiology and Biotechnology, v.29, p.335-345, 2013.

ZHANG, H.W.; SONG, Y.C.; TAN, R.X. Biology and chemistry of endophytes. Natural product reports, v. 5, p. 753-771, 2006. 